\title{
Discrete Set Organization Name Data Type
}

National Cancer Institute

\section{Source}

National Cancer Institute. Discrete Set Organization Name Data Type. NCI Thesaurus.

Code C95690.

A data type comprised of a collection of a discrete set of organization names. 